\title{
Pile Group Protection with Riprap Mattress
}

\author{
Christian Chreties, ${ }^{1}$ Luis Teixeira, ${ }^{1}$ and Gonzalo Simarro ${ }^{2}$ \\ ${ }^{1}$ Facultad de Ingeniería, Universidad de la República, Julio Herrera y Reissig 565, 11300 Montevideo, Uruguay \\ ${ }^{2}$ Instituto de Ciencias del Mar, Consejo Superior de Investigación Científica (CSIC), Paseo Marítimo de la Barcelonesa 37-49, \\ 08003 Barcelona, Spain \\ Correspondence should be addressed to Christian Chreties, chreties@fing.edu.uy
}

Received 18 November 2011; Accepted 8 February 2012

Academic Editor: Sami W. Tabsh

Copyright ( $\odot 2012$ Christian Chreties et al. This is an open access article distributed under the Creative Commons Attribution License, which permits unrestricted use, distribution, and reproduction in any medium, provided the original work is properly cited.

New experimental data on plan dimensions for riprap mattresses used in pile group protection against edge failure are analyzed. The influence of flow conditions and the distance between piles in plan dimensions of riprap mattresses are addressed. An alternative methodology for the experimental study of edge failure in pile groups is proposed and verified, significantly reducing the duration of tests (from several days to a few hours) and yielding similar results. For the pile group configuration tested, a design expression for minimum riprap width is obtained. The influence of the distance between the piles on the width of riprap dimensions is shown to be small, and the proposed expression compares well with some of the expressions for single piers found in the literature.

\section{Introduction}

There are basically two different ways of actively protecting alluvial bridges against the local scour that develops at their foundations. First, armouring devices (e.g., riprap mattresses or cable-tied blocks) that strengthen the bed against scour and secondly, flow-altering devices (e.g., slots or sacrificial piers) that weaken the flow capacity to remove sediment around the bridge foundation. Riprap mattresses are probably the most frequently used of all methods and, because riprap elements are expensive, a proper knowledge of the problem is required in order to obtain an economical and safe design [1]. Due to the complexity of the physical mechanisms related to turbulent three-dimensional flow involving sediment transport, the experimental approach is a usual practice to analyze this problem.

While in the last twenty years, intensive work has been done to improve knowledge of riprap design as a countermeasure against local scour both for bridge abutments [2-7] and for single piers [8-11], little work has addressed the case of pile groups. Although pile groups are frequent structures for bridge foundations, to the author's knowledge, the only works devoted to the protection of pile groups are those by Vittal et al. [12], Zarrati et al. [13], and Simarro et al. [14]. Furthermore, Vittal et al. [12] and Zarrati et al. [13] consider flow altering devices (collars), while Simarro et al. [14], who does analyze riprap mattresses, only addresses the problem of riprap block sizing.

There are basically four different failure mechanisms for riprap mattresses, namely, shear failure, edge failure, winnowing failure, and bed-form undermining [8]. A fifth mechanism involving bed degradation could be added. Although these four mechanisms are not entirely independent, there is common agreement on how each mechanism can be avoided. For instance, shear failurewhich occurs when riprap blocks are mobilized due to shear stress transmitted by flow-can be avoided if the riprap blocks are sufficiently large. Winnowing failure, in which the underlying finer bed material escapes through the voids of the riprap, is due to the differences between bed and block sizes and can be avoided using a gravel or synthetic filter. Bed-form undermining is riprap instability due to sand dunes passing through riprap elements and can be avoided by placing the riprap mattress below the trough of the expected bed-forms. Finally, edge failure, the mechanism this work is focused on, occurs when the local scour hole that develops at the river bed beyond the riprap mattress, affects riprap protection by causing its blocks to fall (as shown 


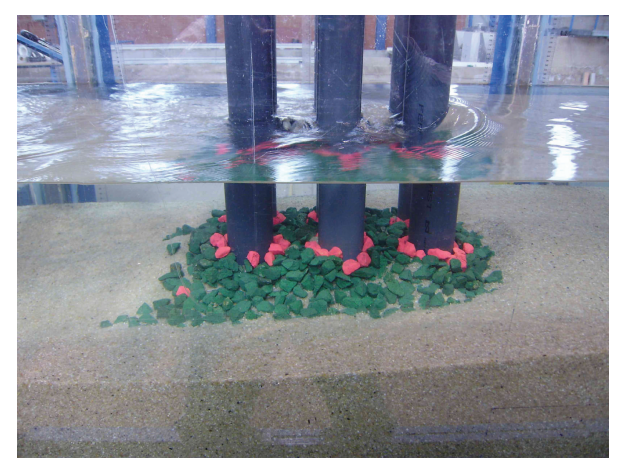

FIGURE 1: Edge failure mechanism in pile group model. Water flowing leftwards.

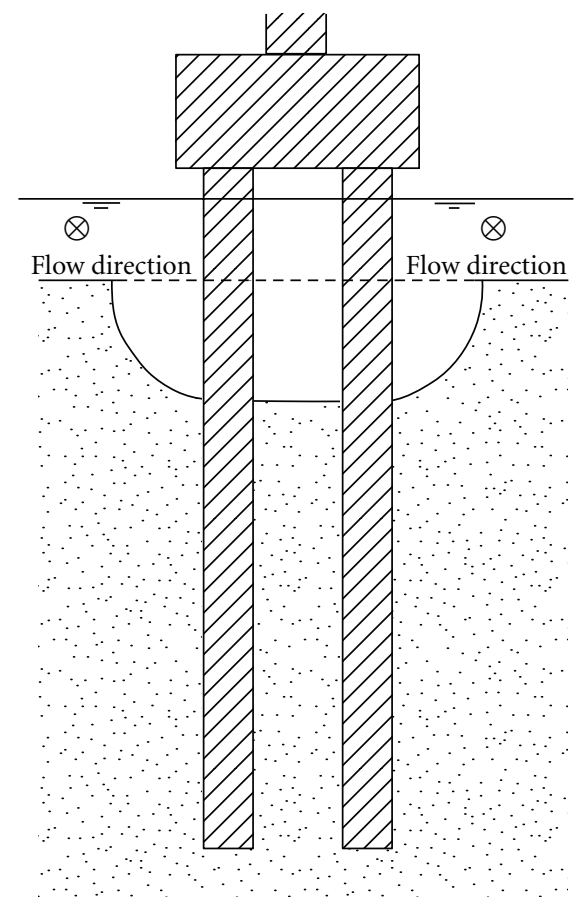

FIGURE 2: Pile group configuration used in experimental campaign.

in Figure 1). Edge failure is avoided by making the riprap mattress sufficiently wide.

The mechanisms are usually analyzed separately, and the worst conditions are considered in each case. For edge failure, the flow conditions are such that the river bed material (finer than the riprap blocks) is close to the entrainment condition, that is, $u \approx u_{c}$, where $u$ is the mean velocity of the approaching flow, and $u_{c}$ is the critical mean velocity for bed material entrainment. Because the local scour process occurring by the riprap mattress can develop slowly over time, long experiments (lasting more than 1 week) are usually required to assess whether a given mattress width is sufficient or not [5].

Recently, Ballio et al. [15] have presented an experimental investigation on temporal scales for live-bed scour al abutments, finding that the time taken to reach equilibrium scour depth rapidly decreases as the flow intensity increases.

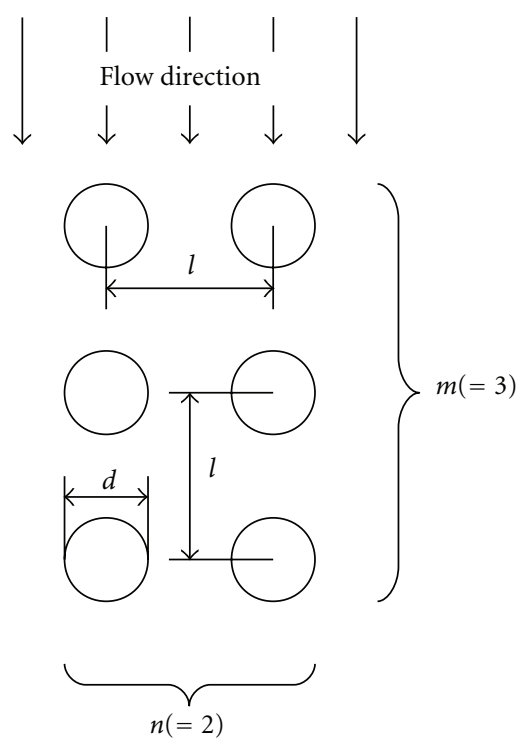

FIgURE 3: Plan view of the pile group and riprap mattress.

Taking into account the above result, in this work we will find an expression for the required extent (width) of the riprap mattress to protect a given pile group geometry. The approach is so that the required time of each experiment is reduced to few hours. In the next section, the proposed methodology is presented; followed by the experimental setup and results and finally, some concluding remarks are made.

\section{Methodology}

In this work we study the case in which only the pile group is exposed to flow (Figure 2), that is, the fifth case of those considered by Coleman [16].

Assuming uniform bed material and a normal flow to the pile group (i.e., with a zero skew angle, as shown in Figure 3), and negligible contraction and viscous effects, the required riprap mattress width, $w$, as defined in the same Figure 3, can be expressed as

$$
w=\phi\left(u, h, \rho, \rho_{s}, d_{50}, g, d, \Gamma, n, m\right)
$$

where $u$ and $h$ are the approaching mean velocity and water depth, $\rho$ is the water density, $d_{50}$ is the size of the bed sediment, $\rho_{s}$ the sediment density (bed and riprap), $g$ the gravity, $d$ the diameter of the individual piers and $\Gamma \equiv l / d, m$ and $n$ dimensionless numbers defining the geometry of the pile group (Figure 3 ). We remark that the width $w$ does not depend on the size of the riprap blocks [7].

Applying dimensional analysis to the above expression, and noting that in the pile group experiments $m=3$ and $n=2$, we get

$$
\frac{w}{d}=\phi\left(\frac{u^{2}}{g d_{50}}, \frac{h}{d}, \frac{\rho_{s}}{\rho}, \frac{d_{50}}{d}, \Gamma\right)
$$


or alternatively [17],

$$
\frac{w}{d}=\phi\left(I \equiv \frac{u}{u_{c}}, \frac{h}{d}, \frac{\rho_{s}}{\rho}, \frac{d_{50}}{d}, \Gamma\right),
$$

where $u_{c}$ is computed ignoring any upstream viscous effects.

Since $\rho_{s} / \rho=2.65$ in all experiments (as in real problems), the dimensionless group $\rho_{s} / \rho$ can be ignored above. Furthermore, overlooking the influence of $d_{50} / d$ [18], as the influence of $d_{50}$ is described through $u / u_{c}$, we finally obtain

$$
\frac{w}{d}=\phi\left(I \equiv \frac{u}{u_{c}}, \frac{h}{d}, \Gamma\right) .
$$

As mentioned above, in the literature for edge failure experiments, flow intensity $I$ is set close to one $(I \approx 1)$ and the experiment is run until an equilibrium condition is reached. "Equilibrium criteria," such as those proposed by, for example, Cardoso and Bettess [19] or Melville and Chiew [20] are required to establish when the experiment is finished. These equilibrium criteria are subject to errors that can be of significance, as noted by Simarro et al. [21].

Here, we consider keeping flow conditions constant during the experiment, but use weak live bed conditions $(I \approx$ 1.3 ) in order to speed up the local scour process occurring by the riprap mattress. In this way, bed-forms will be generated, so that bed-form undermining failure can occur. However, these bed-forms will be relatively small $(2 \mathrm{~cm})$ and their influence will be shown experimentally as negligible in our problem (the results of $w / d$ will be compared for $I \approx 1$ and $I=1.3)$. This procedure will also be used for single piers (case $m=n=1$ ), in order to compare the experimental results with those available in the literature for single piers.

\section{Experimental Setup and Procedures}

The experiments have been carried out at the Civil Engineering School hydraulics laboratory at the University of CastillaLa Mancha (UCLM), Spain. The $30 \mathrm{~m}$-long and $75 \mathrm{~cm}$-wide tilting flume described by Chreties et al. [22] was used.

The single pier (case $m=n=1$ ) or the pile group model (considering always $m=3$ and $n=2$ ) was placed in a recess box about 20 meters downstream of the beginning of the flume. In all cases, $d=6.3 \mathrm{~cm}$. The piles were built in plastic and filled with cement to ensure their stability. The bed sediment used is a quartz sand with $\rho_{s}=2650 \mathrm{~kg} / \mathrm{m}^{3}$, $d_{50}=1.65 \mathrm{~mm}$ and granulometric dispersion $\sigma_{g}=1.27$ ( $<1.3$ so that the sediment can be considered as uniform). Parameter $\Gamma$, which appears in (4), had a range of $2 \leqslant \Gamma \leqslant 3$. This is a usual range in engineering practice and group effects are likely to play a role according Ataie-Ashtiani and Beheshti [23] results for local scour in unprotected pile groups with zero skew angle. For $\Gamma>3$, the group effect is negligible and for $\Gamma=2$ the scour depth is $25 \%$ higher than that for the single pier.

The riprap mattress configuration used in the experimental campaign is shown in Figure 3. The medium size of the riprap blocks, $d_{r 50}$, was always $d_{r 50}=16.44 \mathrm{~mm}$, which proved to resist shear failure in all cases. Winnowing failure was avoided by using a synthetic flexible filter between the riprap and the sand bed below in the riprap zone. Mattress thickness, $t$, was set following recommendations as three times the block size, that is, $t=3 d_{r 50}$. The top of the riprap layer was leveled with the surrounding bed. In the live bed experiments (i.e., $I=1.3$ in Table 1 ), the bedform height was measured upstream the pile group. It was checked to be $\lesssim 2 \mathrm{~cm}$, being the mattress thickness almost $5 \mathrm{~cm}$. Within the scour hole, the dynamics of the sediment transport is modified, and the amplitude of the bed forms was slightly increased. In any case, it was verified that bedform undermining did not occur. In fact, the whole influence of the bed forms in the problem was shown to be small (as shown in the following section). For live-bed experiments it was also checked that bed degradation is negligible at the working zone (which is 20 meters downstream the beginning of the flume).

For a given mattress width, $w$, and $\Gamma$, the volume of riprap stones was calculated from Figure 3, taking into account that $t=3 d_{r 50}$. A flexible plastic plate was inserted vertically in the sand bed along the external perimeter of the idealized riprap mattress, and the same volume of sand was carefully removed from the space the stones were to fill. After deploying the filter, the volume of riprap was finally poured into the excavated sand bed, ensuring that the top level was the same as the surrounding sand bed. In all the tests, a row of red-painted stones were carefully hand-placed around each individual pile (see Figure 4(a)).

Once the pile group and riprap mattress were in position, the flume was slowly filled to the top with water and then driven to get (in this order) the desired flow rate and water depth. The water depth, controlled through a tailgate downstream, was chosen to obtain the desired $h / d$, in expression (4), within the range $1.5 \leqslant h / d \leqslant 2.5$. The flow rate, controlled with an electromagnetic flowmeter with an accuracy of $1.1 \%$, was set so as to get $I=1$ or 1.3 (Table 1 ). In computing $u_{c}$, the expression by Neil [24] was considered. The maximum depth scour into scour holes was measured using a point gage after $1,2,5,7.5,10,15,20,30,45$, and 60 minutes from the beginning, then every hour during the first 12 hours and less frequently after the first 12 hours.

Two different kinds of experiments were carried out: (a) canonical tests ( $\mathrm{C} 1$ to $\mathrm{C} 7$ ), where $I=1$ and (b) live bed tests ( $\mathrm{L} 1$ to $\mathrm{L} 18$ ), where $I=1.3$. For canonical tests, "C", the flume slope was set at $0.07 \%$, while for the live bed tests, "L", the slope was set at $0.11 \%$. In both cases it was assumed that edge failure occurred when at least one red-painted stone was dislodged from its original position (Figure 4(b)). Canonical experiments were run until edge failure occurred ("fail" in Table 1) or until Melville and Chiew [20] equilibrium criteria were satisfied for the scour developed at the bed around the mattress (i.e., the scour depth in 24 hours less than $5 \%$ of the pier diameter $d$ ). If "equilibrium" was reached and the red stones remained unaffected, the mattress was considered to resist ("no fail" in Table 1). For the live-bed tests, experiments were stopped if the mattress failed (i.e., "fail") or after 24 hours ("no fail"), since under weak live conditions the (dynamical) equilibrium has shown to be reached much faster [18]. 


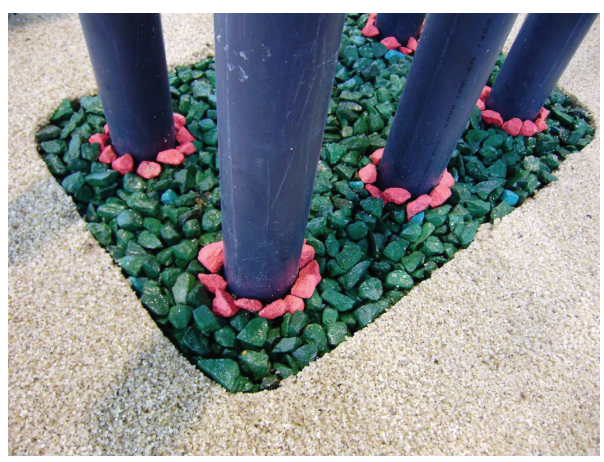

(a)

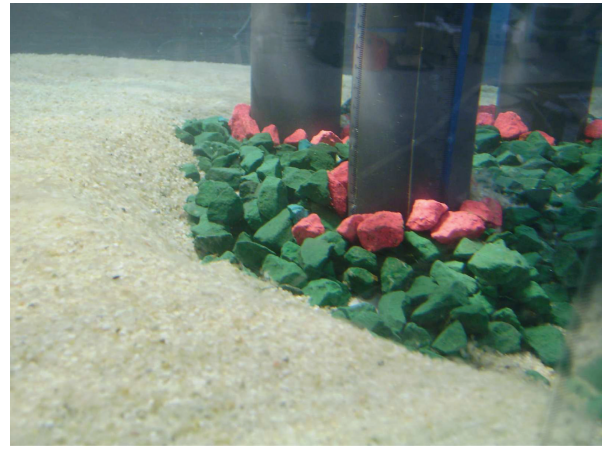

(b)

Figure 4: Edge failure test: experimental setup (a) and block dislodgement (b).

TABLE 1: Experimental conditions and results for pile groups and single piers.

\begin{tabular}{|c|c|c|c|c|c|c|c|}
\hline Test & Model & $\Gamma$ & $I$ & $h / d$ & $w / d$ & result & Duration (h) \\
\hline L1 & Group & 3 & 1.3 & 1.5 & 1.11 & No fail & 24 \\
\hline L2 & Group & 3 & 1.3 & 1.5 & 0.95 & No fail & 24 \\
\hline L3 & Group & 3 & 1.3 & 1.5 & 0.79 & Fail & 5 \\
\hline L4 & Group & 3 & 1.3 & 2.0 & 1.11 & No fail & 24 \\
\hline L5 & Group & 3 & 1.3 & 2.0 & 0.95 & Fail & 19 \\
\hline L6 & Group & 3 & 1.3 & 2.5 & 1.27 & No fail & 24 \\
\hline L7 & Group & 3 & 1.3 & 2.5 & 1.11 & No fail & 24 \\
\hline L8 & Group & 3 & 1.3 & 2.5 & 0.95 & Fail & 4 \\
\hline L9 & Group & 2 & 1.3 & 1.5 & 0.95 & No fail & 24 \\
\hline L10 & Group & 2 & 1.3 & 1.5 & 0.79 & Fail & 1 \\
\hline L11 & Group & 2 & 1.3 & 2.5 & 1.11 & No fail & 24 \\
\hline L12 & Group & 2 & 1.3 & 2.5 & 0.95 & No fail & 24 \\
\hline L13 & Group & 2 & 1.3 & 2.5 & 0.79 & Fail & 5 \\
\hline L14 & Single & - & 1.3 & 2.5 & 0.95 & No fail & 24 \\
\hline L15 & Single & - & 1.3 & 2.5 & 0.79 & Fail & 4 \\
\hline L16 & Single & - & 1.3 & 1.5 & 0.95 & No fail & 24 \\
\hline L17 & Single & - & 1.3 & 1.5 & 0.79 & No fail & 24 \\
\hline L18 & Single & - & 1.3 & 1.5 & 0.63 & Fail & 1 \\
\hline $\mathrm{C} 1$ & Group & 3 & 1.0 & 2.0 & 0.95 & No fail & 120 \\
\hline $\mathrm{C} 2$ & Group & 3 & 1.0 & 2.0 & 0.79 & Fail & 24 \\
\hline C3 & Group & 3 & 1.0 & 2.5 & 0.95 & No fail & 117 \\
\hline $\mathrm{C} 4$ & Group & 3 & 1.0 & 2.5 & 0.79 & Fail & 68 \\
\hline C5 & Group & 3 & 1.0 & 2.5 & 0.63 & Fail & 1 \\
\hline C6 & Single & - & 1.0 & 2.5 & 0.95 & No fail & 110 \\
\hline C7 & Single & - & 1.0 & 2.5 & 0.79 & Fail & 24 \\
\hline
\end{tabular}

If, under given flow conditions, a mattress with a given width $w$ resisted, a new width one centimeter smaller was tested in order to find the largest failing width and the minimum stable one.

\section{Experimental Results and Discussion}

The description of riprap edge failure observed in the experimental campaign corresponds, essentially, to that for single piers as described by Unger and Hager [1].
Table 1 shows the main features of each experiment. Recalling expression (4), it includes $w / d, I=u / u_{c}, h / d$ and $\Gamma$ ( $\Gamma$ only for the tests for pile groups). The table also describes whether the mattress failed or not as well as the experiment duration. A total of 18 tests were carried out for pile groups ( 5 of them canonical, "C") and 7 for single piers ( 2 canonical ones).

In order to show the implications of setting $I=1.3(\mathrm{~L}-$ tests) instead of $I \approx 1$ (C-tests) on the required time, Figure 5 shows the time history of the scour for tests L6 to L8 and C3. These four tests share $h / d=2.5$ and $\Gamma=3$. Also, tests 


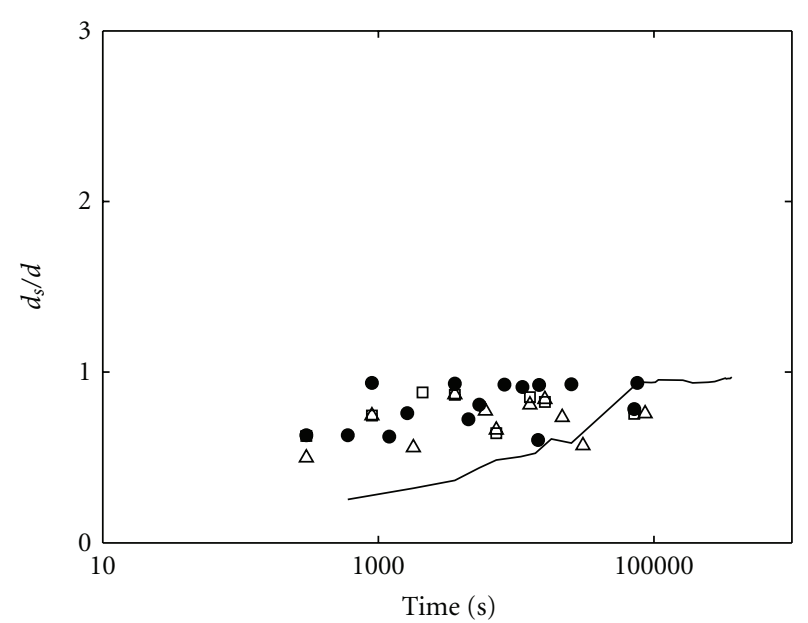

Figure 5: Canonical and live-bed results for $\Gamma=3 . I=1, w / d=$ 0.95 (line); $I=1.3, w / d=0.95$ (black circles) $I=1.3, w / d=1.11$ (squares); $I=1.3, w / d=1.27$ (triangles).

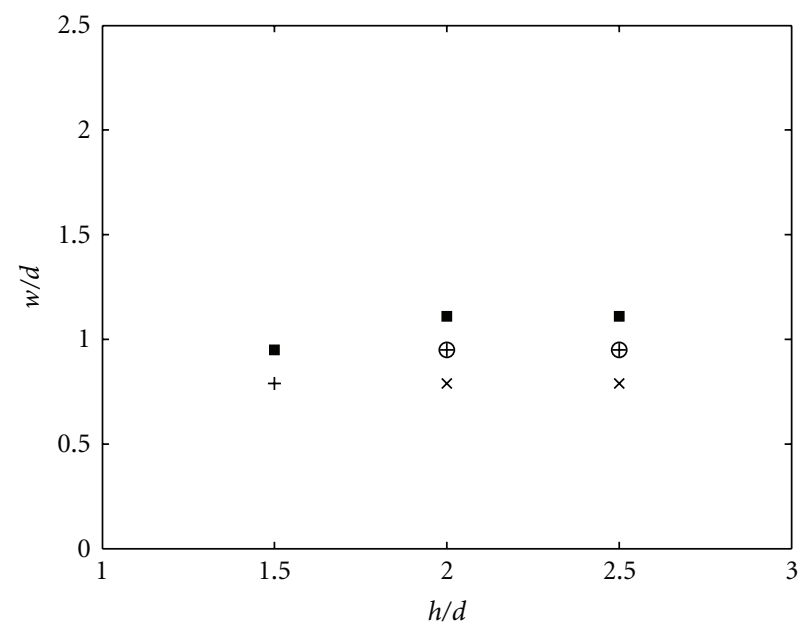

FIGURE 6: Canonical and live-bed results for the pile group with $\Gamma=3 . I=1.3$ no fail (black squares); $I=1.3$ fail $(+) ; I=1$ no fail (circles); $I=1$ fail (crossed).

L6 to L8 have $I=1.3$ (with different $w / d$ ), while $I \approx 1$ for test C3. From Figure 5, several aspects are to be noted: first, the equilibrium depth for $\mathrm{C} 3$ is $d_{s e} / d \approx 0.97$, notably smaller than if there had been no protection $\left(d_{s e} / d \approx 2.4\right.$ according to Melville [18]); secondly, and more interestingly for our purposes, the maximum scour depths, normalized by $d$, for tests L6 to L8, are $0.87,0.88$, and 0.94 , respectively (noting that the scour depths now oscillate due to the passage of bed-forms). Hence, the aim of using $I \approx 1$ being to obtain the worse scour conditions in the surrounding bed mattress, using $I=1.3$ will obtain similar conditions (significantly, the difference between L8 and C3, as those also sharing $w / d=0.95$, is just $3 \%)$. Finally, regarding time evolution, from Figure 5 it is clear that time evolution is much faster for L-tests: the maximum scour is already reached after $\approx$ $3000 \mathrm{~s}$, that is, less than one hour. Together with the fact that bed-form undermining will be small, as shown below, these

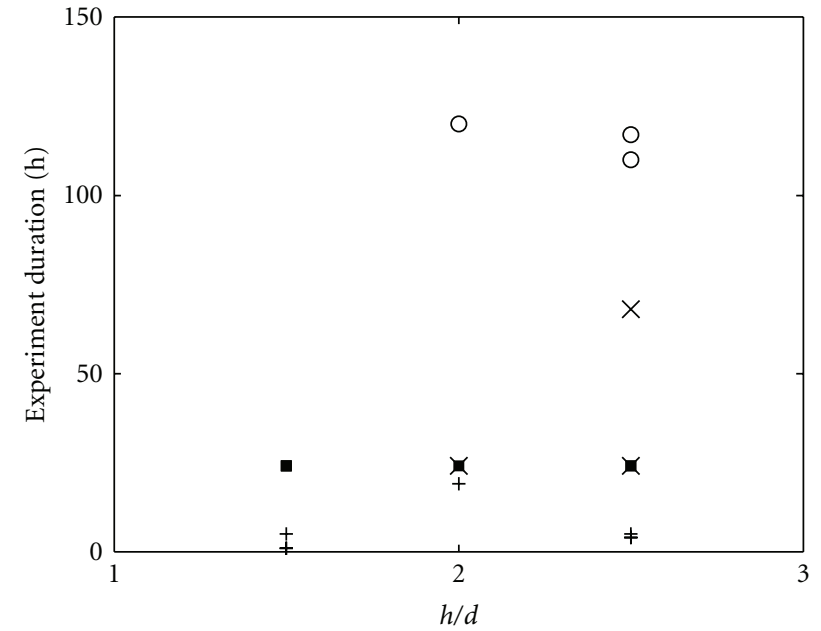

FIGURE 7: Experimental duration reduction. Canonical and live-bed experiments. $I=1.3$ no fail (black squares); $I=1.3$ fail $(+) ; I=1$ no fail (circles); $I=1$ fail (crossed).

results justify the use of $I=1.3$ for speeding up riprap edge failure experiments in pile groups.

One main experimental result validating the use of livebed tests is plotted in Figure 6. This figure shows, as a function of $h / d$, the results obtained for pile groups with $\Gamma=3$ using $I \approx 1$ (C-tests) and $I=1.3$ (L-tests). The minimum stable and maximum failing widths are plotted. As depicted from the figure, the results are similar and using Ltests fall slightly on the safety side. Because in L-tests there is sediment transport, bed-form undermining can have some (small) influence which makes the results slightly on the safety side.

We remark that L-tests are much shorter than canonical ones, and here comes the main advantage. This fact is stressed in Figure 7, showing the experimental time for Cand L-tests for all the experiments in Table 1. The longer tests (those where the mattress resists) took around $120 \mathrm{~h}$ for $\mathrm{C}$-tests and only $24 \mathrm{~h}$ for the L-tests. Moreover, the results in Figure 5 suggest that this time could have been further reduced to few hours.

To further validate the use of weak live-bed conditions $(I=1.3)$, Figure 8 shows the results obtained for single piers (L14 to L18, C6 and C7) together with the upper and lower limits proposed by Lauchlan [26] (also see Melville et al. [25]), that consider

$$
1.0 \leqslant \frac{w}{d} \leqslant 1.5
$$

First, the results using L- and C-tests in Figure 8 are, as in Figure 6, similar (in fact, now they coincide for $h / d=$ 2.5 , the only case where they can be compared). Secondly, our experimental results fall slightly below the lower limit proposed by Lauchlan [26], that is, $w / d=1.0$. However, we recall that the expression by Lauchlan [26] is an envelope of the experimental data. 


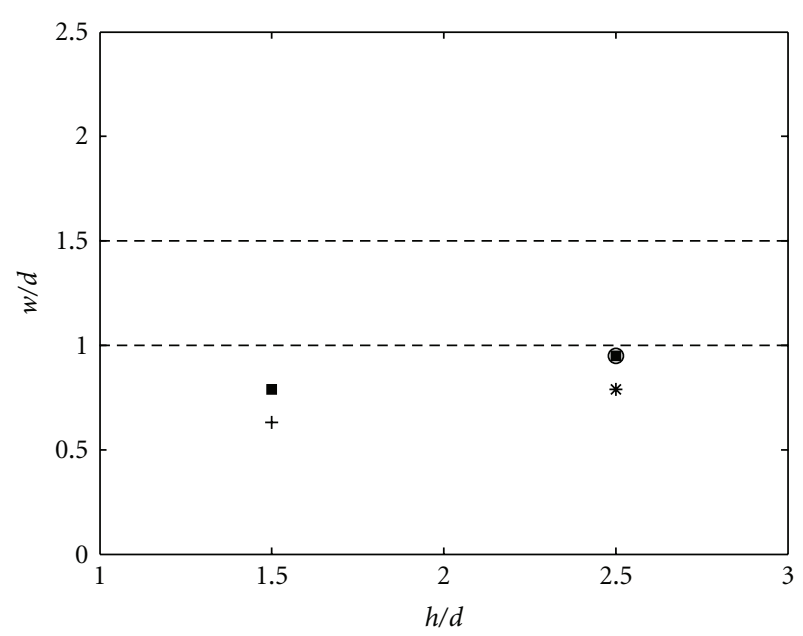

Figure 8: Canonical and live-bed results for the single pier compared with the expression by Melville et al. [25] upper and lower limits (dashed line). $I=1.3$ no fail (black squares); $I=1.3$ fail (+); $I=1$ no fail (circles); $I=1$ fail (crossed).

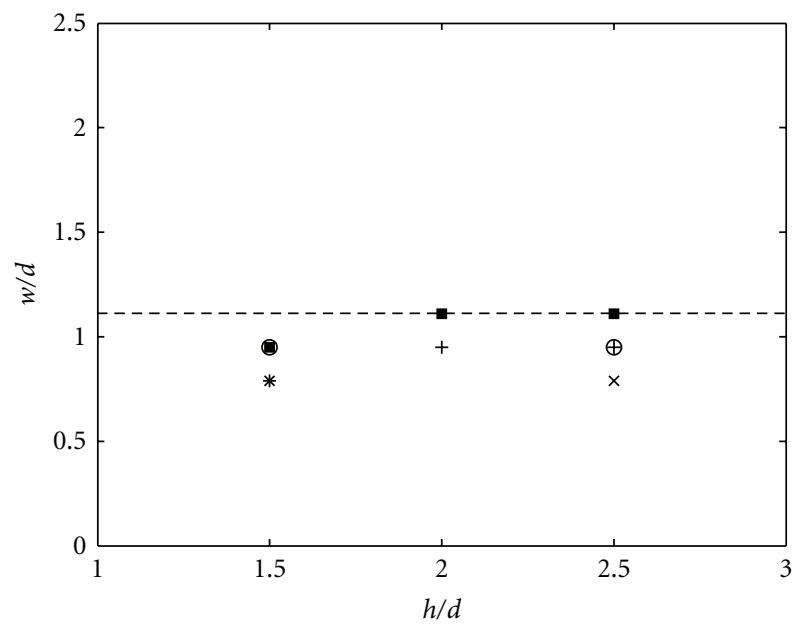

Figure 9: Experimental results for pile groups and proposed expression (7): $w / d=1.11$ (dashed line). $\Gamma=3$ no fail (black squares); $\Gamma=3$ fail $(+) ; \Gamma=2$ no fail (circles); $\Gamma=2$ fail (crossed).

Finally, recalling expression (4) and recognizing that we are considering the most demanding situation in terms of flow intensity, we can write

$$
\frac{w}{d}=\phi\left(\frac{h}{d}, \Gamma\right),
$$

and, from the experimental data, we can give an expression for $\phi$ in our range. Figure 9 shows the experimental results to be used (all data for the pile group). From Figure 9, $w / d$ has a weak dependence on both $\Gamma$ and $h / d$ (for $h / d \leqslant 2$ ). This is relatively unsurprising: on the one hand, although there is no clear consensus, group effects are usually small for $\Gamma \geqslant 2$; on the other hand, for $h / d \geqslant 2$ essentially we have "narrow piles" and, since we normailize $w$ with $d$, the role of $h / d$ becomes negligible [18]. The above is in good agreement with the results by Simarro et al. [14] for riprap block design. The proposed expression is simply

$$
\frac{w}{d}=1.1
$$

for $2 \leqslant \Gamma \leqslant 3,1.5 \leqslant h / d \leqslant 2.5, d_{50} / d=0.026, d_{r 50} / d=0.26$, $m=3, n=2$, and for zero skew angle. The above expression should also work well, in accordance with the arguments given above, for other values of $d_{50} / d=0.026$ and $d_{r 50} / d=$ 0.26 ; for $h / d>2.5$ and for $\Gamma>3$.

\section{Concluding Remarks}

Using $I=1.3$ instead of $I=1$, the duration of experiments to assess required riprap mattress' width to resist edge failure can be significantly reduced. Although we are mixing two different mechanisms (edge and weak bed-form undermining), the influence of the later appears to be small and gives results on the safety side, therefore justifying the use of weak live-bed conditions. An expression for the riprap width is given for a given pile group geometry, where $m=3$ and $n=2$.

\section{Acknowledgments}

C. Chreties was supported by the Agencia Nacional de Investigación e Innovación (ANII) Uruguay. G. Simarro is supported by the Spanish government through Ramón y Cajal program. All three authors thank Eduardo Diaz for his help in preparing the experiments.

\section{References}

[1] J. Unger and W. H. Hager, "Riprap failure at circular bridge piers," Journal of Hydraulic Engineering, vol. 132, no. 4, pp. 354-362, 2006.

[2] J. E. Pagan-Ortiz, Stability of Rock Riprap for Protection at the Toe Abutments Located at the Floodplain, Federal HighWay Administration, U.S. Department of Transportation, Washington, DC, USA, 1991.

[3] B. Melville, S. van Ballegooy, S. Coleman, and B. Barkdoll, "Countermeasure toe protection at spill-through abutments," Journal of Hydraulic Engineering, vol. 132, no. 3, pp. 235-245, 2006.

[4] B. W. Melville, S. van Ballegooy, S. E. Coleman, and B. Barkdoll, "Riprap size selection at wing-wall abutments," Journal of Hydraulic Engineering, vol. 133, no. 11, pp. 1265-1269, 2007.

[5] A. H. Cardoso and C. M. S. Fael, "Protecting vertical-wall abutments with riprap mattresses," Journal of Hydraulic Engineering, vol. 135, no. 6, pp. 457-465, 2009.

[6] A. H. Cardoso, G. Simarro, O. Le Doucen, and A. Schleiss, "Sizing of riprap for spill-through abutments," in Proceedings of the Institution of Civil Engineers: Water Management, vol. 163, no. 10, pp. 499-507, November 2010.

[7] A. H. Cardoso, G. Simarro, C. Fael, O. Le Doucen, and A. J. Schleiss, "Toe protection for spill-through and vertical-wall abutments," Journal of Hydraulic Research, vol. 48, no. 4, pp. 491-498, 2010.

[8] Yee-Meng Chiew, "Mechanics of riprap failure at bridge piers," Journal of Hydraulic Engineering, vol. 121, no. 9, pp. 635-643, 1995. 
[9] Y. M. Chiew and F. H. Lim, "Failure behavior of riprap layer at bridge piers under live-bed conditions," Journal of Hydraulic Engineering, vol. 126, no. 1, pp. 43-55, 2000.

[10] C. S. Lauchlan and B. W. Melville, "Riprap protection at bridge piers," Journal of Hydraulic Engineering, vol. 127, no. 5, pp. 412-418, 2001.

[11] Y. M. Chiew, "Local scour and riprap stability at bridge piers in a degrading channel," Journal of Hydraulic Engineering, vol. 130, no. 3, pp. 218-226, 2004.

[12] N. Vittal, U. C. Kothyari, and M. Haghighat, "Clear-water scour around bridge pier group," Journal of Hydraulic Engineering, vol. 120, no. 11, pp. 1309-1319, 1994.

[13] A. R. Zarrati, M. Nazahira, and M. B. Mashahir, "Reduction of local scour in the vicinity of bridge pier groups using collars and riprap," Journal of Hydraulic Engineering, vol. 132, no. 2, pp. 154-162, 2006.

[14] G. Simarro, C. Chreties, and L. Teixeira, "Riprap sizing for pile groups," Journal of Hydraulic Engineering, vol. 137, no. 12, pp. 1676-1679, 2012.

[15] F. Ballio, A. Radice, and S. Dey, "Temporal scales for live-bed scour at abutments," Journal of Hydraulic Engineering, vol. 136, no. 7, Article ID 003007QHY, pp. 395-402, 2010.

[16] S. E. Coleman, "Clearwater local scour at complex piers," Journal of Hydraulic Engineering, vol. 131, no. 4, pp. 330-334, 2005.

[17] G. Simarro, L. Teixeira, and A. H. Cardoso, "Flow intensity parameter in pier scour experiments," Journal of Hydraulic Engineering, vol. 133, no. 11, pp. 1261-1264, 2007.

[18] B. W. Melville, "Pier and abutment scour: integrated approach," Journal of Hydraulic Engineering, vol. 123, no. 2, pp. 125-136, 1997.

[19] A. H. Cardoso and R. Bettess, "Effects of time and channel geometry on scour at bridge abutments," Journal of Hydraulic Engineering, vol. 125, no. 4, pp. 388-398, 1999.

[20] B. W. Melville and Y. M. Chiew, "Time scale for local scour at bridge piers," Journal of Hydraulic Engineering, vol. 125, no. 1, pp. 59-65, 1999.

[21] G. Simarro, C. M.S. Fael, and A. H. Cardoso, "Estimating equilibrium scour depth at cylindrical piers in experimental studies," Journal of Hydraulic Engineering, vol. 137, no. 9, pp. 1089-1093, 2011.

[22] C. Chreties, G. Simarro, and L. Teixeira, "New experimental method to find equilibrium scour at bridge piers," Journal of Hydraulic Engineering, vol. 134, no. 10, pp. 1491-1495, 2008.

[23] B. Ataie-Ashtiani and A. A. Beheshti, "Experimental investigation of clear-water local scour at pile groups," Journal of Hydraulic Engineering, vol. 132, no. 10, pp. 1100-1104, 2006.

[24] C. R. Neil, "Mean velocity criterion for scour of coarse uniform bed material," in Proceedings of the 12th IAHR Congress, pp. 46-54, Fort Collins, Colo, USA, 1967.

[25] B. W. Melville, S. E. Coleman et al., Bridge Scour, Water Resources Publications, LLC, Colo, USA, 2000.

[26] C. S. Lauchlan, Pier scour countermeasures, Ph.D. thesis, Civil and ResourcesEngineering, University of Auckland, Auckland, New Zealand, 1999. 

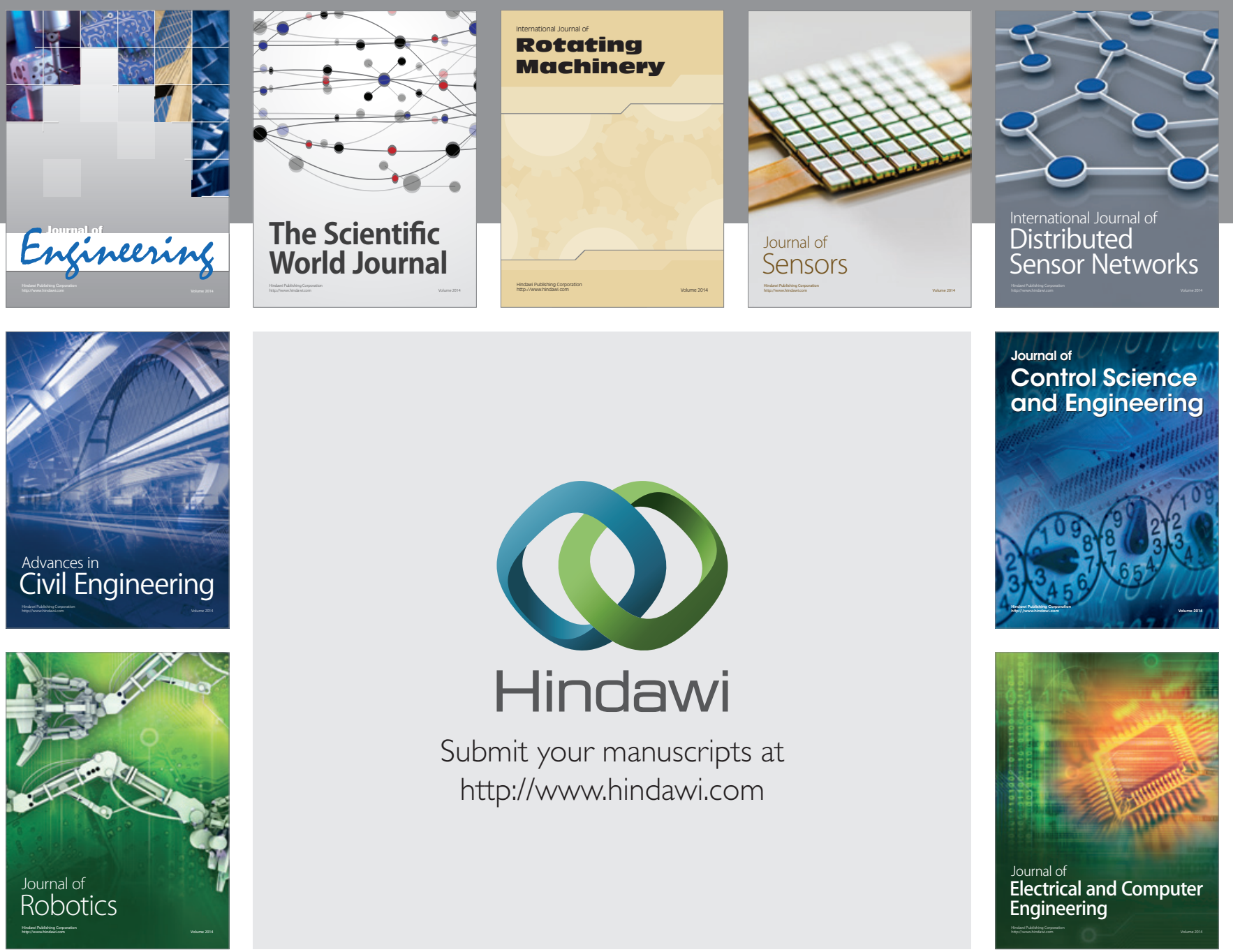

Submit your manuscripts at

http://www.hindawi.com
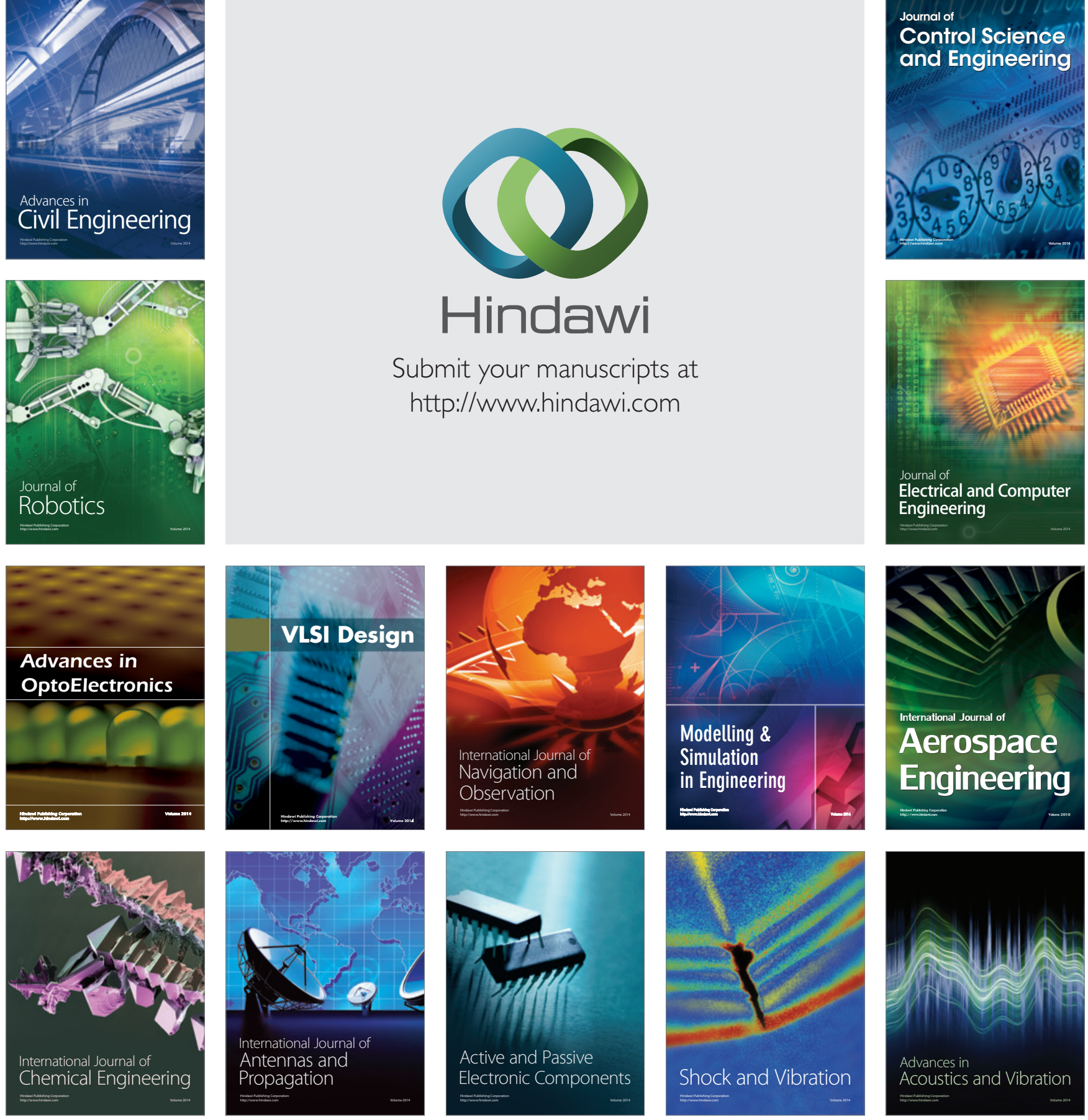